\title{
O trabalho do assistente social nos centros de atenção psicossocial - CAPS do município de Belém/PA: contribuições para o tratamento da saúde mental dos usuários
}

The work of the social worker at the centers of psychosocial care- the CAPS in the city of Belem/PA: contributions for the treatment of the user's mental health

\begin{abstract}
Resumo:
Este artigo objetiva apresentar as contribuições do trabalho do assistente social para o tratamento da saúde mental dos usuários dos Centros de Atenção Psicossocial. Os CAPS se configuram a partir dos anos 1990 como um novo espaço sócio-ocupacional na área da saúde mental para o assistente social decorrente da substituição dos serviços manicomiais. Os dados apresentados decorrem de uma pesquisa na qual três assistentes sociais participaram de uma entrevista semiestruturada, conduzida a partir de um roteiro pré-elaborado. Como procedimento metodológico optou-se pela abordagem qualitativa à luz da teoria marxista. Os resultados da pesquisa revelaram que trabalho profissional do assistente social nessa área envolve saberes específicos da área de Serviço Social em interlocução com os saberes de outros profissionais e possibilitam responder demandas trazidas pelos usuários dos CAPS quanto àquelas identificadas por esse profissional. A articulação com a rede de serviços favorece à resolutividade das situações que envolvem o processo saúde-doença dos referidos usuários, para além do tratamento em saúde mental, repercutindo diretamente na melhoria das condições de vida dos mesmos, em que pese às dificuldades enfrentadas na operacionalização da Política de Saúde mental devido às manobras idealizadas pelo grande capital e operadas pelo Estado de cunho neoliberal.
\end{abstract}

Carolina Flexa da Silva Vera Lúcia Batista Gomes**

Palavras-chave: CAPS. Trabalho profissional do Assistente Social. Estado. Saúde mental.

\begin{abstract}
:
This article aims to present the contributions concerning the function of the social worker towards the treatment of the patient's mental health in the centers of psychosocial care. The CAPS appear in the 90's as a new social area in the mental health field for the social worker as a result of the replacement of the mental health services. The data shown are from a survey which three social workers took part in an interview conducted from a pre-elaborated path. As a methodological procedure, one it was decided to use the qualitative approach under the Marxist view. The results of the research show that the professional work of the social worker in this area concerns certain know-how of the social worker's area with
\end{abstract}

\footnotetext{
* Assistente Social formada pela Universidade Federal do Pará. Mestre em Serviço Social pela Universidade Federal do Pará. E-mail: carol flexa@hotmail.com

** Docente da Faculdade de Serviço Social da UFPA. Doutora em Sociologia do Trabalho - Université de Picardie Jules Vernes. E-mail: veragomesbelem@hotmail.com
} 
other professionals in the same area and enables to answer demands brought by CAPS' users, as well as others identified by the professionals. The contact with the network of services makes the resolution of the situation much lower, concerning the illness-health process of the users, beyond the mental health care system, having, thus, a straight relation in the welfare of the condition of the patient, looking at the hardships that are faced in the operation of the mental health policies, due to the manoeuvres aimed by the big amount of the capital and organized by the state as a neoliberal way.

Keywords: CAPS. Social worker's professional job. State. Mental health.

\section{Introdução}

Os Centros de Atenção Psicossocial - CAPS constituem um serviço estratégico na política de saúde mental consolidando as propostas da Reforma Psiquiátrica. Sendo assim, nessas instituições o processo de trabalho em saúde mental é orientado na busca de ruptura do tradicional modelo biomédico de medicalização e focalização dos sintomas. Diferentemente dos manicômios, caracterizados por internação e isolamento, os CAPS são dispositivos reservados a acolher os usuários com sofrimentos mentais, promovendo sua integração social e familiar, incentivando quando necessário a busca da autonomia e oferecendo atendimento multiprofissional. Esses espaços contam com uma equipe composta em geral pelos seguintes profissionais: assistente social, psicólogo, médico, enfermeiro, terapeuta ocupacional, técnico de enfermagem e técnico administrativo. Ainda sobre o novo modelo de atenção em saúde mental, ele tem suas bases em uma concepção ampliada de saúde, fundamentada no SUS, e implicada numa relação com o contexto econômico, social e cultural do País e abrangendo situações como: moradia, saneamento, renda, alimentação, educação, acesso ao lazer e bens (BRASIL, 2005).

Em busca da apreensão do movimento real do objeto de estudo deste trabalho, fez-se um esforço em articular o material empírico ao referencial teórico - metodológico em sua elaboração. Desta forma, o propósito deste artigo foi analisar o trabalho dos profissionais assistentes sociais nos Centros de Atenção Psicossocial, em Belém-Pará, particularmente, do assistente social e a sua contribuição para o tratamento da saúde mental dos usuários. $\mathrm{O}$ assistente social como profissional inserido na divisão social e técnica do trabalho, integra as equipes de saúde. A resolução no 287 de 08 de outubro de 1998 do Conselho Nacional de Saúde caracteriza o assistente social, entre outros, como 
profissional de saúde, devendo ater-se a dispositivos legais e ao Conselho de Classe desta categoria.

O interesse em estudar o tema da saúde mental, enquanto um dos espaços sócioocupacionais dos assistentes sociais é devido, de um lado, por tratar-se de um tema instigante, sobretudo com a criação de um novo modelo de atenção em saúde mental, antes tratado como loucura e da parca literatura sobre o tema na área do Serviço Social apesar de se ter um acúmulo de discussões em diversas áreas a partir da Luta Antimanicomial e da Reforma Psiquiátrica - e de outro lado, pelo fato de que desde o ano de 2013, uma das autoras vem exercendo atividades profissionais nessa área. No prefácio do livro A dimensão técnico-operativa do Serviço Social, a Profa Valéria Forti (2012) atenta para o fato de que vem sendo ampliado o número de pesquisadores e autores na temática da prática profissional. Contudo, ainda podemos considerá-la como exígua na produção da profissão. Portanto, a importância de discussões desse tema face à lacuna na literatura do Serviço Social é significativamente sentido em uma profissão interventiva como o Serviço Social.

Nesse sentido, entende-se que a pesquisa constitui um dos principais instrumentos que possibilita a produção de conhecimentos acerca da referida realidade e, em consequência, subsidia elementos quer seja para a formulação/avaliação das políticas públicas de saúde mental, quer seja para qualificar ainda mais a intervenção profissional da equipe multiprofissional nessa área, contribuindo, dessa forma, para a efetivação do acesso ao direito à saúde.

Assim, os resultados deste estudo são baseados nas reflexões e análises efetuadas sobre os dados obtidos com a realização de uma pesquisa de campo realizada em três CAPS $^{1}$ instalados no município de Belém/PA, que subsidiou a elaboração da Dissertação de Mestrado $^{2}$ de uma das autoras, bem como nos estudos e debates efetuados no Grupo de Estudos e Pesquisas "Trabalho, Estado e Sociedade na Amazônia”, o qual é vinculado

\footnotetext{
${ }^{1}$ Os serviços de cada CAPS estão vinculados à Secretaria de Estado de Saúde Pública (SESPA) ou à Secretaria Municipal de Saúde (SESMA), sendo eles: um CAPS i, um CAPS AD e um CAPS III. Os CAPS i atendem diariamente as crianças e os adolescentes com transtornos mentais; CAPS AD: são os CAPS voltados para o atendimento aos usuários dependentes de álcool e outras drogas; CAPS III: são os CAPS que dispõem de atendimentos diários e noturnos para adultos com transtornos mentais severos e persistentes (BRASIL, 2004).

${ }^{2}$ A mencionada Dissertação teve como objeto o trabalho profissional do assistente social na saúde mental nos CAPS do município de Belém, defendida em agosto de 2015.
} 
ao Programa de Pós-Graduação em Serviço Social - UFPA, congregando estudantes, assistentes sociais e docentes pesquisadores sobre trabalho e políticas públicas na Amazônia.

Deste modo, este artigo encontra-se estruturado em quatro partes. A primeira se reporta ao Serviço Social na área da Saúde Mental, fazendo destaque para a legitimação da profissão na sociedade brasileira, destacando que a substituição dos serviços manicomiais pelos serviços alternativos instituídos a partir de 1990, propiciou um maior espaço profissional ao Serviço Social na área da saúde mental do que a internação. A segunda parte trata do trabalho do assistente social nos CAPS do município de Belém e suas contribuições para o tratamento da saúde mental dos usuários, evidenciando as demandas que chegam aos assistentes sociais e que extrapolam o atendimento clínico à saúde mental, haja vista que as condições de vida dos usuários expressam as contradições da relação capital $x$ trabalho que requerem articulação com os serviços de outras políticas públicas, a exemplo: documentação civil, geração de renda e benefícios previdenciários, alimentação, medicamentos, moradia/abrigamento, educação e capacitação profissional etc. Por último, apresenta as considerações finais, evidenciando que a articulação com a rede de serviços favorece a resolutividade das situações que envolvem o processo saúdedoença dos referidos usuários, para além do tratamento em saúde mental, na medida em que repercute diretamente na melhoria das condições de vida dos mesmos, em que pese às dificuldades enfrentadas na operacionalização da Política de Saúde mental devido às manobras idealizadas pelo grande capital e operadas pelo Estado de cunho neoliberal.

\section{O serviço social na área da saúde mental - elementos para reflexão}

Ao analisar o trabalho do assistente social torna-se fundamental considerar os seguintes aspectos: "O primeiro é considerar a questão social como base de fundação sócio-histórica do Serviço Social e o segundo é apreender a 'prática profissional' como trabalho e o exercício profissional inscrito em um processo de trabalho (IAMAMOTO, 2004, p.57, grifo do autor)." Cria-se, então, um espaço sócio-ocupacional ocupado por vários profissionais, dentre os quais, o profissional de Serviço Social, que passa a atuar no 
sentido de minimizar as expressões da questão social ${ }^{3}$. A profissão do assistente social se legitima, em princípio, vinculada ao surgimento e à expansão das políticas sociais e estatais.

Com base na teoria marxista, lamamoto (2004) afirma que qualquer processo de trabalho sugere uma matéria-prima ou objeto sobre o qual sucede a ação do sujeito e que o próprio trabalho demanda meios ou instrumentos para que possa ser concretizado. No que se refere ao processo de trabalho do Serviço Social ${ }^{4}$ :

O objeto do trabalho, aqui considerado, é a questão social. É ela, em suas múltiplas expressões, que provoca a necessidade da ação profissional junto à criança e ao adolescente, ao idoso, a situações de violência contra a mulher, a luta pela terra etc. Essas expressões da questão social são a matéria-prima ou o objeto do trabalho profissional. Pesquisar e conhecer a realidade é conhecer o próprio objeto de trabalho, junto ao qual se pretende induzir ou impulsionar um processo de mudanças. Nesta perspectiva, o conhecimento da realidade deixa de ser um mero pano de fundo para o exercício profissional, tornando-se condição do mesmo, do conhecimento do objeto junto ao qual incide a ação transformadora ou esse trabalho (IAMAMOTO, 2004, p. 62, grifo da autora).

Dessa forma, o assistente social intervém nas mais variadas expressões da questão social, tais como os indivíduos as experimentam no trabalho, na família, na habitação, na saúde, na assistência social pública etc. No que se refere aos aspectos sociais na área da saúde, tornam-se necessários conhecimentos multidisciplinares e plurais, além de práticas complementares e interdisciplinares. Nesta perspectiva, o Serviço Social possui um lugar nessa área que, em articulação com as demais áreas de saber, permite obter uma visão integral do sujeito que adoece, favorecendo a compreensão das implicações socioeconômicas e culturais da saúde, fator relevante para a humanização e qualificação do atendimento aos seus usuários, conforme preconizam as diretrizes do SUS.

Na relação do Serviço Social com a área da Saúde Mental, a substituição dos serviços manicomiais pelos serviços alternativos propiciou, de acordo com Bisneto (2009), a participação do Serviço Social em proporção maior do que na internação, o que está permitindo o emprego, desde os anos 1990, de assistentes sociais em Saúde Mental,

\footnotetext{
${ }^{3}$ A questão social em Serviço Social é entendida como o objeto de intervenção do assistente social, no Brasil que se expressa na realidade social, tais como: miséria, pobreza, fome, desemprego, precarização do trabalho etc, ou seja, são os resultados vividos pela classe trabalhadora no processo de acumulação capitalista (LARA et al., 2015).

${ }^{4}$ Não é consenso na categoria profissional dos assistentes sociais o posicionamento sobre o Serviço Social ser considerado como processo de trabalho. A discussão está em aberto e apresenta material teórico consistente nas duas polaridades do debate, para isso ver: Lessa (2012) e lamamoto (2004).
} 
numa espécie de nova "onda" de contratações similar à produzida nos anos 1970 pelas resoluções do Instituto Nacional de Previdência Social (INPS). Pois, desde o fim dos anos 1990 já existem no Sudeste do Brasil vários serviços alternativos na atenção em saúde mental. O autor Bisneto (2009, p. 40) refere que:

\begin{abstract}
Tanto o Serviço Social contemporâneo quanto à psiquiatria do Movimento de Reforma Psiquiátrica têm influênciais do Movimento Institucionalista e do Sanitarismo (Bravo, 1996 apud Bisneto, 2009). Além disso, o Movimento de Luta Antimanicomial propiciou uma concepção e prática em Saúde Mental mais politizada, bem como a contratação de mais assistentes sociais. O Movimento de Reforma Psiquiátrica veio propor novos encaminhamentos metodológicos, com a possibilidade de o assistente social intervir de forma efetiva nas refrações da "questão social" na área da Saúde Mental.
\end{abstract}

Quanto à inserção de assistentes sociais na Saúde Mental, historicamente foi determinada pela criação de equipes multidisciplinares no atendimento psiquiátrico. Essas equipes não se instituíram somente porque o Serviço Social constituiria uma nova forma de encaminhar o sofrimento da loucura, mas também porque a profissão operaria como intermediária das demandas sociais emergentes na área manicomial e como barateador dos custos da assistência em geral,

\footnotetext{
Assim, a origem da interdisciplinaridade não advém apenas de uma racionalidade científica, do reconhecimento da complexidade dos problemas de saúde por parte da própria medicina e dos órgãos planejadores da saúde, visando a uma maior eficiência e efetividade dos programas. Há interesses e razões políticas e financeiras também (BISNETO, 2009, p. 51).
}

Em relação ao fazer profissional do assistente social em Saúde Mental, em particular no CAPS, Bisneto (2009) expõe que o profissional trabalha de forma pluralista quando usa as elucidações do marxismo para compreender a exclusão do louco, para sustentar a demanda por direitos sociais e cidadania aos portadores de sofrimento mental e, ao mesmo tempo, usa as explicações da medicina e da psicologia para conceber a loucura como doença mental. Os médicos psiquiatras mais progressistas também tendem a aceitar o ponto de vista do Serviço Social crítico para explicar a exclusão social, mas dificilmente admitem as contribuições do marxismo para explicar a loucura ou para atuar na assistência psiquiátrica, como por exemplo as condições materiais de vida dos usuários, enquanto um fator desencadeador do adoecimento mental. O autor ainda evidencia que na área de Serviço Social e Saúde Mental é interessante trabalhar na 
perspectiva de pluralismo como descrito acima, ou usar novos campos de coerência, como a Análise Institucional, porque os paradigmas clássicos não conseguem resolver sozinhos os problemas na conjunção de uma assistência biopsicossocial. Vejamos a seguir:

No Movimento de Reforma Psiquiátrica o assistente social não deve ser apenas o profissional do "cuidado", da "atenção", mas o técnico que pode desenvolver a crítica à sociedade burguesa e à loucura na sua correlação com o capitalismo. O assistente social não deve apenas se munir de técnicas para atuar na Saúde Mental, mas sim desenvolver metodologias, avançando na análise crítica da sociedade nas suas refrações com a loucura, para daí conceber as mediações para intervenção no campo psiquiátrico (BISNETO, 2009, p. 61).

Nesse sentido, orientado por uma perspectiva histórico e crítica, pode-se propiciar uma ruptura com as práticas funcionais ao sistema burguês e ao capital também na atuação em Saúde Mental. "A metodologia do assistente social em psiquiatria não pode ser praticista ou iluminada por um conhecimento técnico pretensamente neutro" (MONTAÑO, 1998 apud BISNETO, 2009, p. 62). Conclui-se que, para romper de vez com as teses endogenistas, faz-se indispensável arguir às perspectivas tradicionais da psiquiatria e do Serviço Social e adotar o Movimento de Reforma Psiquiátrica, porém perceber o significado do papel da categoria profissional dos assistentes sociais de trabalhar com o olhar social, a contradição, a politização, a ordem do trabalho produtivo, da subjetividade no campo econômico e histórico da análise social.

Tem-se ainda na relação Serviço Social e Saúde Mental, o seguinte cenário segundo Bisneto (2009): no Brasil há a conjunção de quatro fatores sociais, quais sejam o capitalismo monopolista, a globalização financeira e mercantilista, o neoliberalismo e a reestruturação produtiva. Resultando na estrutura social em sérios problemas da ordem do Serviço Social e da Saúde Mental. São quatro fenômenos sociais complexos, de longo percurso histórico, que, sob o ponto de vista da repercussão nas políticas sociais, resulta em dificuldades na assistência social e psiquiátrica. Logo,

Dentro dessa política os governos estão interessados em diminuir os custos da assistência psiquiátrica dos hospitais do Estado. Aproveitam-se da onda neoliberal para não internar pacientes, mesmo sem criar serviços alternativos suficientes, diminuindo verbas e não contratando novos profissionais. Mas, contraditoriamente (ou não!), os governos continuam interessados em repassar verba pública para os empresários do setor psiquiátrico e "terceiro setor" filantrópico, através de convênios que pagam internações para os usuários dos serviços de Saúde Mental, para continuar enriquecendo a 
burguesia e outros setores conservadores que compõem a base de sustentação de seus mandatos. (BISNETO, 2009, p.42-43).

Assim, considerando o espaço sócio-ocupacional dos CAPS, nestas condições expostas anteriormente, o assistente social exerce o seu trabalho em forma de assalariamento, ou seja, o seu trabalho é considerado uma mercadoria, submetido a um contrato de trabalho instituído pelo modo de produção capitalista desde o final do século XVIII e início do século XIX com a Revolução Industrial, na Inglaterra. Segundo lamamoto (2012, p. 18):

Nesse processo de compra e venda de sua força de trabalho especializada, o assistente social entrega ao seu empregador o valor de uso específico de sua força de trabalho qualificada. Por um lado, essa atividade - como qualquer outro trabalho - implica transformação de uma matéria sobre a qual incide e à qual tem acesso pela mediação de seu empregador, além de concretizar-se em um resultado que tem objetividade material ou social. Decorre daí a necessidade de se reconhecer a qualidade dessa atividade, sua particularidade na divisão técnica e social do trabalho coletivo, ou seja, sua natureza peculiar, os meios necessários à sua efetivação, a matéria que transforma e os resultados que produz, nas várias inserções profissionais.

\section{O trabalho do assistente social nos CAPS do município de Belém: contribuições para o tratamento da saúde mental dos usuários}

A compreensão sobre as contribuições do trabalho do assistente social nos CAPS de Belém, para o acesso dos seus usuários à saúde, teve por base a pesquisa de campo realizada em três CAPS, a saber: o CAPS i e o CAPS AD, vinculados à Secretária Municipal de Saúde, e o CAPS III, vinculado à Secretaria de Estado de Saúde Pública, cujos sujeitos foram três assistentes sociais. Para a coleta de dados foi utilizada como instrumento, a entrevista do tipo semiestruturada, conduzida a partir de um roteiro pré-elaborado, cujo conteúdo constava de: dados profissionais, fundamentação teórica - metodológica, trabalho profissional e avaliação sobre o trabalho realizado nos CAPS. Como procedimento metodológico optou-se pela abordagem qualitativa à luz da teoria marxista, sendo que os dados coletados foram submetidos à análise de conteúdo, com foco nos núcleos de sentido e frequência dos temas presente nas comunicações dos sujeitos, sintetizadas nas categorias temáticas explicativas da realidade. Para preservar o anonimato dos pesquisados utilizou-se a identificação por letras dos sujeitos da pesquisa e os CAPS por números. Desta forma, os assistentes sociais foram identificados pelas 
letras A, B e C. O CAPS AD para a sua identificação foi atribuído o número 1, o CAPS III pelo número 2 e o CAPS i pelo número 3.

Nos CAPS, os assistentes sociais realizam ações específicas junto aos usuários dos serviços, a partir de um olhar diferenciado da profissão, no que concerne à interpretação das mazelas sociais, pois:

\begin{abstract}
Para apreender o significado social da prática profissional supõe inseri-la no conjunto das condições e relações sociais que lhe atribuem um sentido histórico e nas quais se torna possível e necessária. O Serviço Social afirma-se como um tipo de especialização do trabalho coletivo, ao se constituir em expressão de necessidades sociais derivadas da prática histórica das classes sociais no ato de produzir e reproduzir seus meios de vida e de trabalho de forma socialmente determinada (IAMAMOTO, 2007, p.88).
\end{abstract}

Sendo assim, de acordo com os assistentes sociais pesquisados, a equipe nos CAPS de Belém-PA trabalha de forma interdisciplinar, contudo são asseguradas as especificidades do Serviço Social, conforme pode ser evidenciado na figura a seguir.

Figura 1 - Identificação das ações específicas desenvolvidas pelos assistentes sociais nos CAPS -Belém/PA.

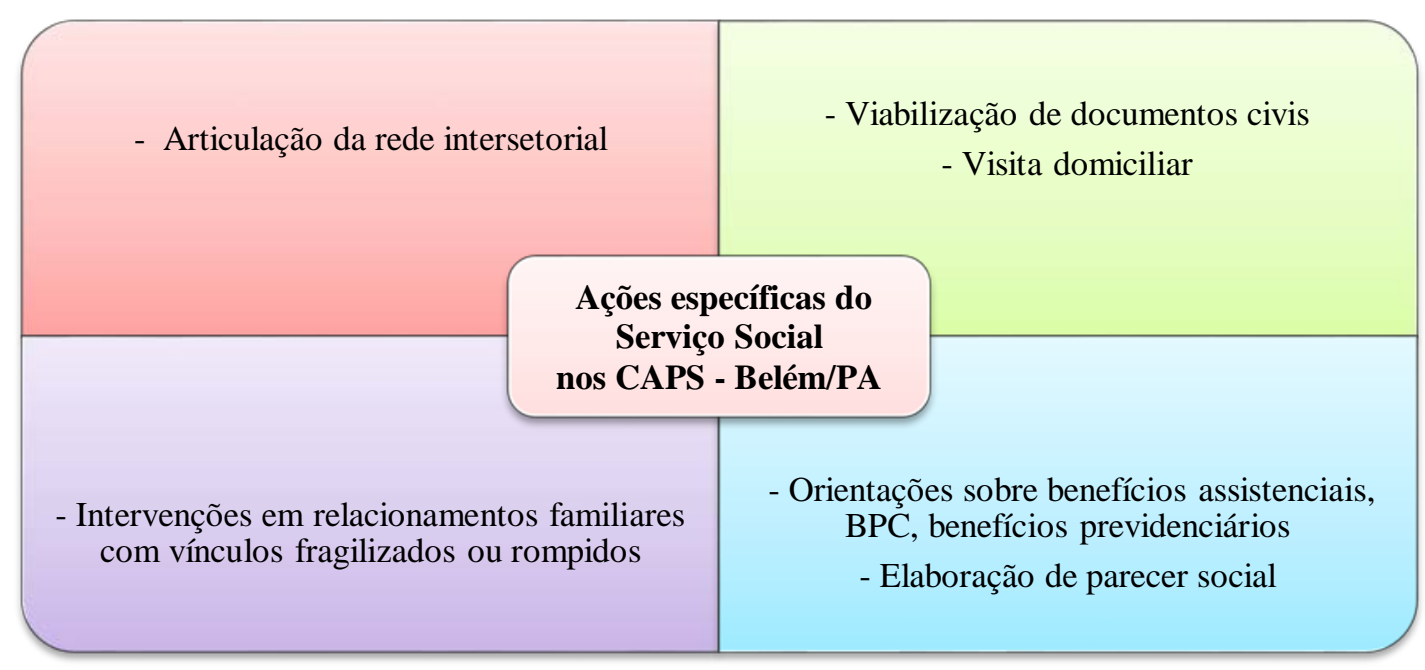

Fonte: Elaboração das autoras, com base na pesquisa de campo em maio/2015.

Dentre as ações específicas dos assistentes sociais desenvolvidas nos CAPS, foi apontada a articulação com a rede de serviços como um ponto central no cotidiano desses profissionais, pois esta ação é responsável pelo resolutividade de outras demandas específicas, por exemplo: a viabilização de documentos civis, de benefícios assistenciais e previdenciários, de abrigamento, de moradia e de ações dentro do território. A propósito, Faleiros (2010, p.25) refere que: 
A rede é uma articulação de atores em torno, vamos nos expressar assim, de uma questão disputada, de uma questão ao mesmo tempo política, social, profundamente complexa e processualmente dialética. Trabalhar em rede é muito mais difícil do que empreender a mudança de comportamento, bastando para isto um bom marketing, ou realizar a intervenção no meio, ou estimular o eu, e mesmo reiniciar serviços. É a superação do voluntarismo e do determinismo, da impotência diante da estrutura e da onipotência da crença de tudo poder mudar. Na intervenção de redes, o profissional não se vê nem impotente nem onipotente, mas como um sujeito inserido nas relações sociais para fortalecer, a partir das questões históricas do sujeito para ampliação de seu poder, saber, e de seus capitais.

O trabalho junto à rede de serviços é articulado com as intervenções na família dos usuários dos CAPS, tanto em casos de pessoas que vivem sob o mesmo teto ou no resgate de vínculos familiares. A rede de serviços é composta por instituições públicas e da sociedade, que articuladas disponibilizam atendimentos, benefícios, serviços, programas e projetos com vistas a garantia de direitos sociais. Sendo assim, a visita domiciliar é um instrumento por vezes requisitado ao profissional, prioritariamente, de forma eletiva, ou seja, quando é verificado que o usuário por algum motivo está sem condições de circular no território, não frequentando mais o CAPS, há em alguns casos a necessidade da busca ativa ou nos casos de necessidade para emissão de parecer social. Evidentemente, a realização da visita domiciliar exige condições para a sua realização. Segundo Lukács (2004 apud SANTOS, 2010, p. 83),

[...] o trabalho para se realizar pressupõe um conhecimento concreto, ainda que jamais perfeito, de determinadas finalidades e de determinados meios, indica a imprescindível presença dos conhecimentos teóricos e dos meios para a efetivação do trabalho.

Neste sentido a autora se refere a que a teoria contribui com,

[...] o redimensionamento dos instrumentos ao oferecer a forma de tratá-los, as estratégias $\mathrm{e}$ as abordagens, porquanto podemos utilizar instrumentos diferentes em nossa intervenção, mas que os utilizemos de acordo com o método por nós aceito (p.83). (...) A teoria entendida como "um instrumento para compreender com maior profundidade, riqueza e amplitude os fenômenos da vida" (LUKÁCS, 1978 apud SANTOS, 2010, p.84).

Desta forma, segundo esta autora a teoria oferece a compreensão da dinâmica social em que se insere o objeto de intervenção, isto é, propicia o entendimento sobre o significado social dessa intervenção para as demandas dos usuários. Este entendimento remeteu ao conhecimento das principais demandas postas aos assistentes sociais nos 
CAPS - Belém e às respostas dadas pelos assistentes sociais às mesmas. Os relatos abaixo, dos assistentes sociais pesquisados destacam que as demandas são:

\begin{abstract}
As mais diversas possiveis, dentro da esfera social e da clínica da saúde mental, que vão desde uma escuta de continência e conforto, passando por uma orientação ou encaminhamento para alguns benefícios de saúde ou social até a realização de visitas ou intervenção em domicílios. Considero que no geral são viabilizadas, mas nem tudo são flores. Há muitas dificuldades e limitações institucionais e às vezes até materiais. No trabalho em equipe é demandada a interpretação da questão social do usuário para poder traçar linhas de intervenção possiveis para se alcançar o objetivo de seu projeto de tratamento (A1).
\end{abstract}

A principal demanda para o Serviço Social aqui no CAPS é a orientação para benefícios, benefícios assistenciais no caso do BPC e benefícios previdenciários, $e$ todo mundo que demanda isso para gente recebe retorno e há uma aceitação das informações, isso numa abordagem específica (B2).

Conforme pode ser observado nos relatos acima, as demandas postas ao Serviço Social nos CAPS são diversificadas, estendendo-se desde uma escuta, uma orientação sobre benefícios ou encaminhamento para um serviço de saúde, o que corrobora a importância do trabalho de articulação com a rede de serviços, além do estudo da situação dos usuários para a elaboração do plano terapêutico singular. Porém, os assistentes sociais fizeram destaques às dificuldades de limitações institucionais e materiais que encontram para responder a tais demandas. Ou seja, a defesa da garantia de direitos à saúde dos usuários dos CAPS vem sendo efetuada por esses profissionais, mas a concentricidade de tais direitos é imbricada às mediações inerentes à realidade dos CAPS, pois:

A construção do objeto profissional não pode, assim, ser referida a conceito extremamente genérico sem levar em conta a história, as discussões, os debates dos projetos de sociedade e de intervenção profissional nas diferentes conjunturas. É preciso considerar, ainda, nas relações de poder e saber particulares, o processo de construção de estratégias de ação, as situações sociais complexas na relação de diferentes atores sociais envolvidos numa questão. Abre-se, assim, a possibilidade de o Serviço Social trabalhar ao mesmo tempo em redes de relações particulares e gerais para fortalecer a relação de força dos oprimidos nessa rede (FALEIROS, 2010, p.24).

Pelo exposto deduz-se que há necessidade de articulação teoria/prática para desvendar o conhecimento da realidade em que se vai intervir e, assim, poder contribuir para a viabilização de respostas às demandas dos usuários, tendo por base a correlação de forças existentes em determinados momentos históricos. No que tange á particularidade do trabalho nos CAPS, os prontuários dos usuários constituem-se 
fundamentais para a sistematização de informações sobre os mesmos para subsidiar o planejamento das ações, conforme evidenciam os relatos abaixo:

O próprio prontuário do usuário que é atendido, mapas de produção diária, relatórios e parecer técnicos, laudos de atendimentos mensais (A1).

Nós não temos um documento específico do Serviço Social" "O prontuário e alguns relatórios (B2).

“Não, nós não temos nenhuma ficha de nenhum profissional, na verdade, né? Nós trabalhamos na equipe, no grupo. Então, o que tem de específico é na nossa abordagem, no nosso trabalho em grupo, mas não existe um registro do Serviço Social, registro do terapeuta, não existe um registro diferenciado, a não ser no prontuário, no que a gente registra nossas atividades de rotina, mas documento específico de cada profissional isso não tem (C3).

Constata-se que, em geral, o prontuário é sinalizado como principal instrumento de registro da situação do usuário e ponderando a prática interdisciplinar é de suma importância para subsidiar o trabalho dos diversos profissionais, inclusive o assistente social. Pois, possibilita ter acesso às informações sobre o usuário e seu tratamento em saúde mental. Porém, avalia-se que esse ponto poderia ser revisto e aprimorado pelo profissional assistente social, com a incorporação no cotidiano profissional, de instrumentos específicos como o diário de campo e/ou elaboração de uma ficha de atendimento social, que possibilitaria fazer registros adequadamente reservados e acesso restrito apenas do profissional em questão, priorizando a dimensão ética e do sigilo profissional.

Figura 2 - Identificação dos principais aspectos das condições de trabalho dos assistentes sociais nos CAPS

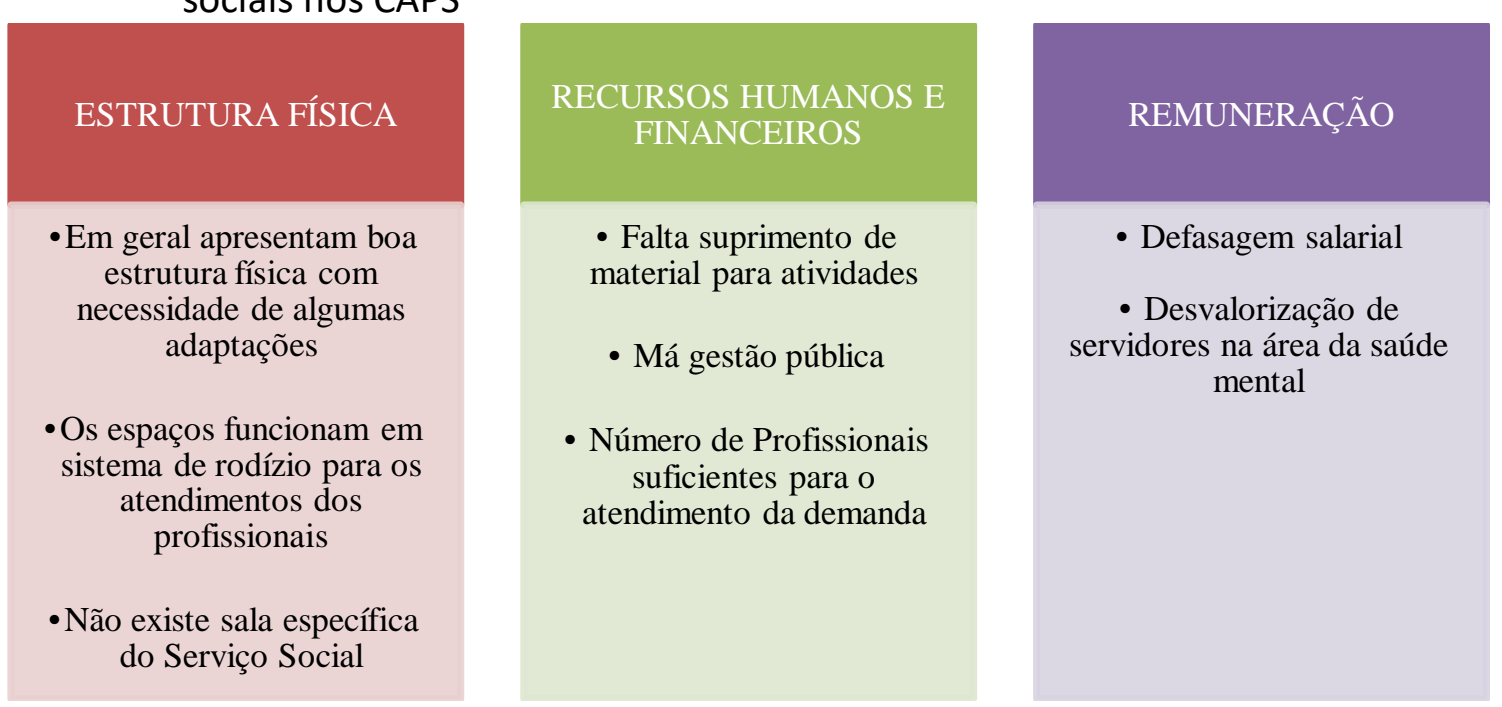

Fonte: Elaboração das autoras, com base na pesquisa de campo em maio/2015. 
A Figura acima aponta que a estrutura física dos CAPS conta com boas instalações para a realização do trabalho profissional; porém, se vistas com olhos técnicos para necessidade dos serviços de saúde mental, constatar-se-á que as mesmas precisam de adaptações, inclusive funcionando como estratégia o sistema de rodízio dos espaços disponíveis até como uma forma de resistência para o funcionamento do serviço, conforme evidencia o depoimento da profissional A1, acerca da estrutura física dos referidos CAPS,

Não são as melhores, mas considero que não são as piores, dentro da realidade do SUS numa realidade macro do Brasil. Enquanto CAPS, a estrutura física é boa, contudo poderia ter mais alguns espaços para atendimentos, tanto individuais quanto coletivo.

Nós não temos uma sala por profissão, como o trabalho é multidisciplinar nós temos uma sala de técnicos, que ali a gente pode realizar nossos estudos, a gente pode organizar o nosso acompanhamento, guardar material, nós não temos uma sala específica e isso não nos faz falta, termos uma sala, não significa que só com ela nós vamos realizar nossos trabalhos; a gente convive bem com o multidisciplinar (B2).

O serviço social necessita de um espaço em que a gente possa trabalhar com o usuário de forma preservada e aqui a gente tem esse espaço, só que esse espaço, ele é um espaço que não é do serviço social, eu tenho mais dois profissionais que trabalham comigo e a gente trabalhava de forma planejada com horários diferenciados, claro, para atender essas necessidades porque se houvesse realmente uma condição em que você, o profissional tivesse uma sala exclusiva que pudesse trabalhar de uma forma mais à vontade, e que te deixasse mais livre pra organizar e planejar isso ia dar uma resposta com certeza melhor. Muitas vezes a gente quer fazer um trabalho diferenciado e a gente não tem esses recursos para isso, e de certa forma prejudica o trabalho porque você não pode tá se planejando para aquilo que não existe, você tem que considerar a sua realidade e a realidade do serviço público [..] muitas vezes isso traz, profissional um certo desestimulo (C3).

O fato de as instalações físicas dos CAPS não serem adequadas aos trabalhos desenvolvidos pelo assistente social é atribuído pelos pesquisados à má gestão dos serviços públicos, o que implica na falta de material e no não repasse dos recursos financeiros:

Até hoje o CAPS em que trabalho não foi habilitado para receber recursos financeiros e daí a coisa piora ainda mais [...] falta tudo de suprimento material para execução de determinadas ações. Quanto aos recursos humanos, quantitativamente tem profissional suficiente, sinto a falta apenas de um educador físico, falta melhorar qualitativamente o quadro de $R H$ (A1). 
Essa forma de gestão pública é decorrente, segundo Silva (2011), da chamada crise fiscal do Estado, passando a ser o argumento para a defesa neoliberal do corte de gastos sociais, que esconde as reais intenções de diminuição dos custos com a força de trabalho e o redirecionamento do fundo público para atender, em maior escala, as demandas do grande capital.

Deste modo, um dos mecanismos fundamentais utilizados para drenar recursos das políticas sociais brasileiras para o capital que porta juros é a Desvinculação de Receitas da União (DRU) de 2000. A Seguridade Social é a mais atingida por este mecanismo, tendo em vista que ele permite a desvinculação de $20 \%$ dos seus recursos. A DRU transfere os recursos do orçamento da Seguridade Social para o orçamento fiscal com a finalidade de facilitar a formação de superávits e pagar a dívida pública. A DRU possibilitou o repasse de bilhões de reais das políticas sociais para o grande capital e por isso a classificamos como um tipo de programa de transferência de renda para os rentistas.

Esta situação repercute também na remuneração estabelecida na relação de compra e venda da força de trabalho no âmbito do Estado enquanto promotor das políticas sociais públicas. A propósito, as falas dos sujeitos demonstram a precarização do trabalho dos profissionais dos CAPS:

Acredito que a remuneração salarial de servidores públicos que atuam na área da saúde mental deveria ser mais bem valorizada, pois entendo que é um tipo de trabalho que exige um empenho e envolvimento físico e emocional muito intenso cotidianamente do trabalhador (A1).

Em relação aos valores de salários, nós temos uma defasagem salarial muito grande, os dois últimos governos estaduais não atualizam a nossa realidade salarial, tem seguido reajuste do salário mínimo enquanto a gente tem ganhos merecidos e não recebe (B2).

Com base em Marx, Prado (2011) indica a ilusão de que o salário regula uma troca entre equivalentes, fundamenta-se na afirmação de que o salário é o quantum correspondente ao valor do trabalho. Ora, o trabalho é a medida do valor, portanto, não é uma mercadoria que pode ser levada ao mercado. E ressalta,

O salário funciona como uma nuvem de fumaça que encobre as vistas do operário e o impede de enxergar que o seu salário não corresponde ao pagamento de toda sua jornada. Também aos olhos do capitalista a mais-valia, o trabalho não pago, é encoberto pela ilusão da forma salário (PRADO, 2001, p. 110). 
A relação do salário na sociedade capitalista desvelada por Marx corresponde à realidade desses trabalhadores. Pois, de fato os valores não são calculados considerando o custo de vida na cidade de Belém, por exemplo, já que são reajustados com base no salário mínimo que apresenta defasagem ${ }^{5}$. As condições de vida dos trabalhadores, em geral, se tornam mais complexa Esta situação se torna mais complexa, ao considerar que "O capitalismo entrou em uma nova fase que se convencionou chamar de neoliberalismo6"'(DUMÉNIL; LEVY, 2005, p.85).

Pois apesar desses autores afirmarem que é difícil atribuir uma data precisa dessa nova fase, mas o que se constata é que a transição dos anos 1970 para os anos de 1980 marcou um acontecimento emblemático da nova ordem social: o Banco Central dos Estados dos Unidos o Federal Reserve (Fed) elevou "a taxa de juros ao nível requerido para a eliminação da inflação, não importando os custos nos países do centro e da periferia" (DUMÉNIL; LEVY, 2005, p. 85).

Tem-se, então, em um primeiro momento, uma nova hegemonia financeira que "se soma e se combina à hegemonia do país dominante no seio da coalização dos países imperialistas, a dos Estados Unidos" (DUMÉNIL; LEVY, 2005, p. 86), cujas consequências podem ser expressas por: controle dos salários, erosão gradual dos sistemas de proteção social, onda de desemprego, crescimento lento e crises recorrentes nos países da periferia, deslocalização das empresas, elevação das tensões internacionais e novo

\footnotetext{
${ }^{5}$ O valor do salário mínimo brasileiro, fixado em R\$ 788 desde janeiro DE 2015, deveria ser multiplicado por quatro. Só assim seria cumprido o que determina a Constituição de nosso país. De acordo com o Dieese (Departamento Intersindical de Estatística e Estudos Socioeconômicos), o valor do "salário mínimo necessário" deveria ser de $\mathrm{R} \$ 3.118,62$ em janeiro. Durante os meses do ano, o Dieese calcula o chamado "salário mínimo necessário", levando em conta os gastos de uma família com alimentação, moradia, saúde, educação, vestuário, higiene, transporte, lazer e previdência. Ver: http://cspconlutas.org.br/2015/02/salario-minimo-no-brasil-deveria-ser-de-r-3-11862dizdieese/\#sthash.N2UvsKOz.dpuf.

${ }^{6}$ Segundo Cambaúva e Silva Junior (2005, p. 529), "O neoliberalismo consiste em um sistema econômico e político que surge com a proposta de resgatar alguns pressupostos do liberalismo (neo - novo liberalismo) que haviam sido abandonados na ocorrência da crise de 1929, quando então o Estado adotou medidas de bem-estar social propostas por Keynes (1883-1946) para retomar o crescimento do País (Cambaúva, 2002). Tais medidas vigoraram até os anos 70 do século $X X$, quando uma nova crise do capitalismo atingiu a economia mundial. Visando a uma retomada do crescimento econômico, vem à cena um grupo de pensadores - Sociedade Mont Pèlerin - que, desde o final dos anos 40, criticavam as práticas protecionistas e de bem-estar social, as quais seriam responsáveis pela estagnação da economia (Paulani, 1999; Guinsberg, 2001). Dentre esses pensadores, situa-se Hayek (1899-1992), que, como solução à crise capitalista, fundamentou o neoliberalismo".
} 
militarismo. Além disso, o neoliberalismo se impôs sob a proteção do Estado ${ }^{7}$, "produzindo um cenário no qual convivem a acumulação e concentração da riqueza com a ampliação do desemprego, a precarização do trabalho e o agravamento da pobreza" (MOTA, 2009, p. 62).

Para assegurar esse processo foi imperiosa uma nova ofensiva político-social e ideológica caracterizada pela reforma do Estado e pela redefinição de iniciativas conduzidas "pela burguesia para estabelecer novos parâmetros na relação entre o capital, o trabalho e destes com o Estado" (MOTA, 2009, p. 63). Nessa esteira,

(...) A concretização da situação do desemprego significou, tanto para os homens quanto para as mulheres, um profundo sofrimento, seja pelo agravamento dos problemas financeiros, seja, sobretudo, pela manifestação de problemas morais, que revelaram implicações na autoestima, nas relações com os amigos e nas relações familiares. O desemprego foi considerado um fator de grande precarização da vida social e profissional, com a manifestação de doenças psíquicas e físicas, o que foi confirmado por relatos de episódios depressivos, de separações conjugais e, inclusive, de um caso de óbito relacionado ao fracasso do empreendimento e das inúmeras frustrações frente às dificuldades enfrentadas para um novo recomeço (GONÇALVES, 2002, apud LOUGO, 2011, p.48).

Estas situações afetam a saúde mental dos trabalhadores, em geral, haja vista que:

[...] uma sociedade que não consegue dar satisfações necessárias aos seus membros por força cria grande número de indivíduos de caráter oralmente dependente. Os tempos instáveis e as depressões econômicas, privando os homens das suas satisfações, também privando-os do seu poder e prestígio e dos modos habituais por que regular a autoestima, aumentam-lhes as necessidades narcísicas e a dependência oral (CAMBAÚVA; SILVA JUNIOR, 2005, p. 533.).

Sendo assim, no neoliberalismo, os indivíduos, em geral, são culpabilizados pelas situações de crise que atingem a sociedade, tais como: miséria e recessões econômicas e "O fracasso, o insucesso, a perda, a derrota têm suas causas atribuídas à falta de capacidade de o indivíduo lidar com as adversidades (FIGUEIREDO, 1991a apud CAMBAÚVA; SILVA JUNIOR, 2005, p. 533). A propósito, em 2011, o Instituto Nacional de Seguridade Social (INSS) contabilizou um número acima de 211 mil pessoas que foram afastadas do trabalho devido ao adoecimento mental por prazo superior a 15 dias e passaram a receber auxílio doença. Igualmente,

\footnotetext{
${ }^{7}$ Segundo Duménil e Levy, (2005), o Estado é uma instituição que encarna o poder das classes dominantes, por meio do qual a dominação é imposta para o resto da sociedade.
} 
O estudo da OMS também indica que no período 2013-2020, 350 milhões de pessoas sofrerão de depressão e 90 milhões terão alguma desordem pelo abuso de substâncias químicas. É preciso ressaltar que DUAS em cada DEZ pessoas no mundo tem algum problema psiquiátrico. Nos Estados Unidos, $11 \%$ da população com mais de 12 anos já toma remédios antidepressivos. Em 2012, a OMS registrou 781.927 mil suicídios no mundo, que é a 16a causa da mortalidade global. Com um detalhe: nos Estados Unidos e na Rússia é a 10a causa. Na Coréia do Sul é a sétima. No Brasil a 25a (TUBINO, 2014).

Essas considerações acerca do aumento do adoecimento mental, no contexto do neoliberalismo suscitaram interrogar-se sobre as contribuições do trabalho profissional do assistente social nos CAPS - Belém para a saúde mental dos usuários. As respostas obtidas neste sentido pelos pesquisados foram sintetizadas na figura a seguir.

Figura 3 - Contribuições do trabalho profissional dos assistentes sociais para o tratamento da saúde mental dos usuários dos CAPS-Belém/PA
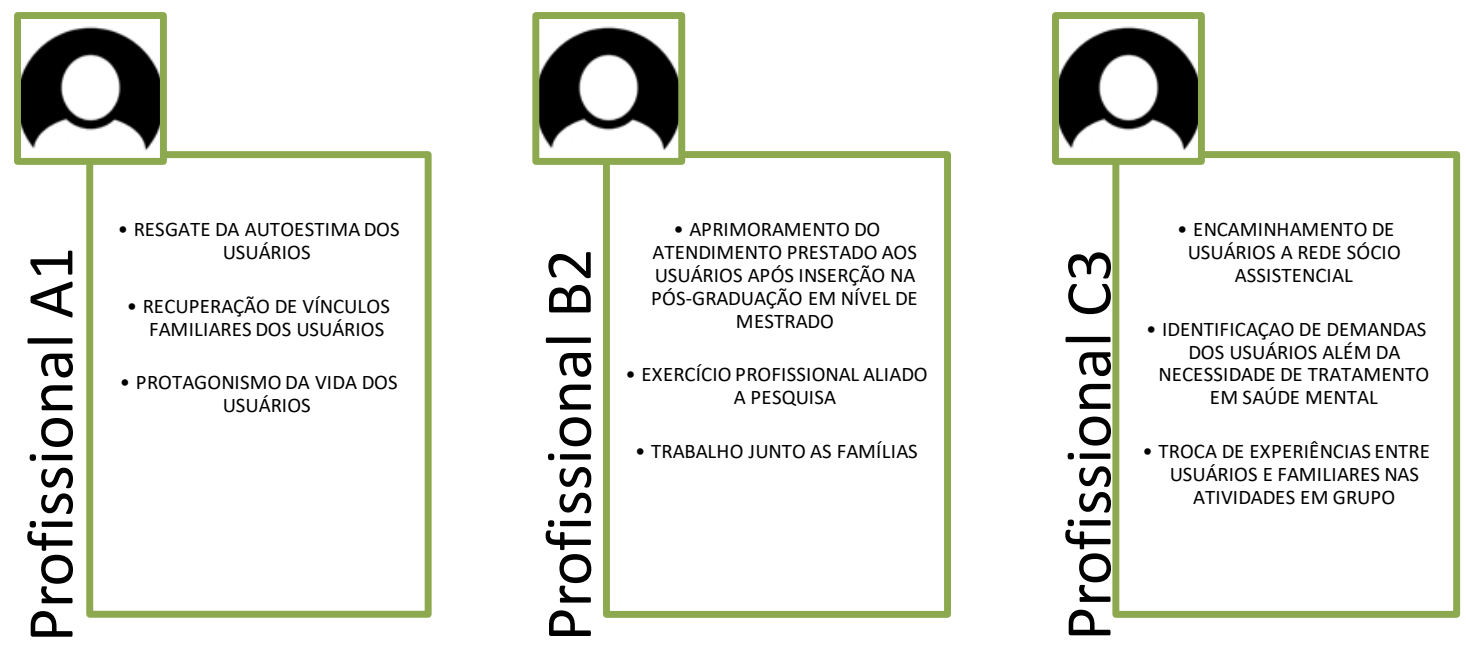

Fonte: Elaboração das autoras, com base na pesquisa de campo em maio/2015.

A figura acima apresenta uma síntese a partir das falas dos profissionais entrevistados, quanto ao que eles consideram as suas contribuições para o tratamento de saúde mental dos usuários. A partir dos atendimentos prestados aos usuários, os profissionais identificam que, a través dos seus processos de trabalho mediante seus processos de trabalho, permitiram subsídios pontuais, tornando o tratamento de fato efetivo. Materializando as contribuições conforme descrito nas falas:

As mais variadas possiveis, desde alguém que conseguiu resgatar sua autoestima; alguém que recuperou vínculos familiares que estavam rompidos 
há muito tempo, até alguém que conseguiu retomar o protagonismo de sua própria vida: saindo das ruas, aprendendo a administrar suas economias e viver a vida sobre nova perspectiva (A1).

Outro depoimento de grande contribuição refere-se à importância da pesquisa vinculada à prática profissional e possibilitada através da inserção em Curso de Mestrado, ratificando o conteúdo apresentado nesse estudo, quanto à necessidade da pesquisa e aprimoramento intelectual,

Eu no ano passado me prontifiquei a fazer o mestrado na área da saúde mental e avalio que hoje seja a minha principal contribuição para esse período aqui no CAPS. Eu pesquisei famílias que têm pessoas com esquizofrenia para saber como se dão os cuidados no ambiente familiar a essa pessoa, e isso me traz, a partir da pesquisa, um novo olhar sobre como lidar com famílias; eu identifiquei coisas que eu achava que não eram vivenciadas por familiares, mas que a pesquisa me mostrou que tem uma realidade que muitas vezes, nós técnicos não conhecemos, o lidar com o cuidado, e hoje eu deixo essa contribuição, apesar de ainda não ter defendido minha dissertação, que eu só defendo em agosto, mas eu já trago na minha fala nas orientações com famílias algumas coisas que eu observei, algumas realidades vivenciadas por familiares e eu já trago para os grupos, para as reuniões técnicas e para o atendimento individual e coletivo [...] e tem vários exemplos de práticas bem realizadas aqui no CAPS, a gente apoiar a familia, orientar e termos grandes sucessos aqui, vários usuários que eu atendi, encaminhei para benefícios que seguiram o caminho da orientação, conseguiram, principalmente em relação a benefício de prestação continuada (B2).

O depoimento abaixo revela como o trabalho em grupo se apresenta no processo de trabalho do assistente social no CAPS, a profissional avalia que esse instrumento é fundamental na identificação de demandas extra CAPS, resultando nos encaminhamentos para a rede, além de propiciar a troca de experiências, socialização de informações. Segue fala do profissional:

$E$ É as situações que nós atendemos, as situações das familias, mais vulneráveis e geralmente eles trazem demandas de outras necessidades, necessidades muitas vezes questões de moradia [..] já aconteceu, né? Do abuso sexual, de uma terceira pessoa dentro da própria família, e que foi revelado a partir do momento que começamos a abordar essa temática no grupo e de que forma isso poderia ser direcionado. $O$ esclarecimento foi feito: você poderia denunciar e o apoio onde você poderia está buscando, e que tipo. De que forma você poderia trabalhar, né? Em si, aquele trauma que Ihe foi vivenciado muitas vezes no momento do grupo, né? Algumas pessoas já adultas, acompanhantes, foram vítimas de abuso sexual dentro da própria família e a maioria das vezes pelo próprio pai, então você percebe que aquela pessoa, ela também precisa de um acompanhamento e aí o serviço social, ela trabalha nesse sentido no momento que ela percebe a necessidade de um encaminhamento com a rede, aí nós encaminhamos para uma terapia fora do CAPS, porque nós atendemos só criança e adolescente, e essa situação é do adulto e aí a gente já procura fazer esse encaminhamento. E nas situações também de desemprego a gente orienta 
nesse sentido, de está dando continuidade, né? Fazendo um curso técnico, oportunizando, orientando aonde existe um atendimento que possa está facilitando esse tipo de situação - "Ah, eu estou desempregado há tantos anos", a pessoa já até perdeu o interesse, ou já se acomodou naquela situação e não acredita que pode voltar ao mercado de trabalho; a gente orienta: "olha, existe um curso, o curso é assim", estimula, aí mostra e entre eles mesmo acaba surgindo naquele momento ali, né? Depoimentos: "eu também vivi", "isso já aconteceu", passei por uma situação que eu fui abandonado e tinha que ficar em casa porque precisava cuidar do usuário e depois consegui", isso também dá um estímulo muito grande na própria vivência do grupo, para aquele que naquele momento está precisando do apoio, o serviço social trabalha muito essa questão do grupo, que essas experiências são trocadas e isso tem ajudado bastante (C3).

A experiência com grupos é apresentada por Siqueira (2008). O trabalho com grupos sempre esteve presente na atuação do assistente social e hoje é uma estratégia de intervenção, que vem sendo cada vez mais utilizada e repensada frente às demandas da população e às perspectivas que as políticas públicas vêm apresentando. A autora alerta:

O trabalho com grupos pode trazer resultados mais consistentes, a possibilidade de se vivenciar a cooperação, fortalecendo vínculos entre os membros; pode ser também um caminho para a participação na defesa e conquista de direitos. Para tanto é fundamental que dentre vários outros aspectos, o profissional conheça e domine como se dá o processo grupal e não somente discuta temas de interesse do grupo (SIQUEIRA, 2008, p.2)

É importante ressaltar que as atividades em grupo no CAPS estão previstas na Portaria/GM no 336 - De 19 de fevereiro de $2002^{8}$ e podem ser executadas por diferentes profissionais sendo conduzida de acordo com a formação do mesmo. Por exemplo, o psicólogo realiza psicoterapia em grupo, o enfermeiro conduz grupo de educação em saúde, o terapeuta ocupacional realiza grupos voltados para reabilitação ocupacional e o assistente social garante atividades de suporte social entre outras. Conclui-se que a abordagem grupal como um instrumento técnico-operativo do assistente social deve ser considerada não apenas em seus aspectos técnicos, o fazer profissional, mas igualmente em suas decorrências sociopolíticas da prática da qual ele potencializa as ações, viabilizando uma intervenção que tem uma direção social situada no movimento contraditório da sociedade.

\footnotetext{
${ }^{8}$ Portaria/GM no 336 - De 19 de fevereiro de 2002. Portaria que define e estabelece diretrizes para o funcionamento dos Centros de Atenção Psicossocial. Estes serviços passam a ser categorizados por porte e clientela, recebendo as denominações de CAPS I, CAPS II, CAPS III, CAPS i e CAPS AD. Documento fundamental para gestores e trabalhadores em saúde mental.
} 
Essas considerações conduziram ao conhecimento sobre as principais dificuldades e os desafios que os assistentes sociais encontram no trabalho que realizam nos CAPS, as quais foram sistematizadas na figura a seguir.

Figura 4 - Identificação das principais dificuldades e desafios que os assistentes sociais encontram no trabalho realizado nos CAPS - Belém/PA:

Preconceito com portador de

transtorno mental ou usuário de drogas

\section{Conhecer a realidade das famílias}
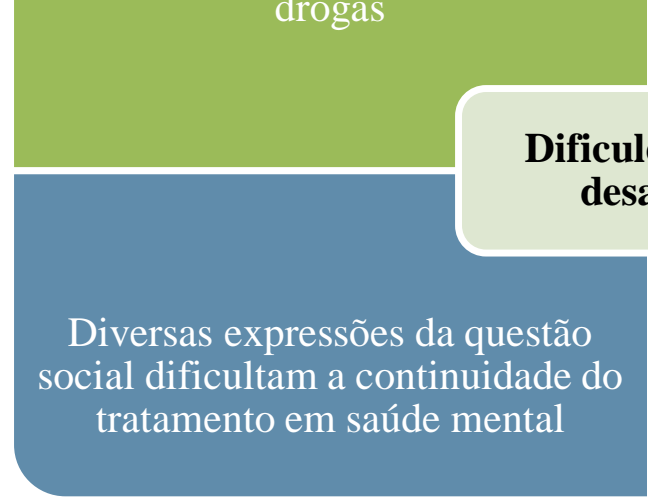

\section{Dificuldades e desafios}

Fonte: Elaboração das autoras, com base na pesquisa de campo em maio/2015.

Conforme pode ser visualizado a figura acima, dentre as principais dificuldades que assistentes sociais encontram no trabalho que realizam nos CAPS - Belém/Pará foram destacadas: preconceito com portador de transtorno mental ou usuário de drogas, o conhecimento da realidade das famílias, o exercício pleno dos direitos de cidadania e diversas expressões da questão social que dificultam a continuidade do tratamento da saúde mental dos usuários. Os depoimentos dos profissionais pesquisados são elucidativos neste sentido:

[...] As mais diversas (dificuldades), dentre as quais, o preconceito, a ignorância e a intolerância, tanto dentro da própria família quanto da sociedade como um todo, que vê o louco ou usuário de drogas como o que não tem razão nem direitos. São, portanto, incapazes de exercer sua cidadania. Os desafios são muitos, mas se quebrarmos os "muros dos manicômios das mentes" do preconceito e da discriminação com essas pessoas em sofrimento, poderemos, sim, ter uma sociedade livre dos manicômios e com cuidado com a saúde mental de todos os seus cidadãos exercendo direitos plenos de cidadania (A1).

[...] a família não tem como chegar até nós, porque existe essa situação financeira que a impede, né, de pagar o transporte coletivo, e essas dificuldades que já citei de muitas vezes o usuário não ter o acesso gratuito, e se ele tem, mas o acompanhante não tem, e o acompanhamento são três vezes na semana [...] nós atendemos usuários de Santa Izabel, de Vigia, temos usuários até que são de outro estado-Maranhão - porque o CAPS lá só é de adulto ou quando 
eles tem um CAPS no próprio estado, é até mais distante eles irem pra lá do que vir pra Belém, então, essa situação de distância, de transporte, de situação financeira tem dificultado muito o nosso trabalho (C3).

Diante do exposto, os pesquisados são da opinião de que combater o preconceito ao portador de sofrimento psíquico nos espaços socio-ocupacionais se constitui uma das atribuições profissionais do assistente social, sobretudo, diante da situação econômica recessiva e regressiva dos direitos sociais, que interferem no tratamento dos usuários, à medida que faltam a estes e aos seus familiares as condições mínimas para a continuação do tratamento. A exemplo se destaca a dificuldade financeira para custear o transporte coletivo, pois o usuário não tem acesso gratuito ao transporte, ou até mesmo se ele o tem, mas o acompanhante não tem, principalmente, porque é necessário o acompanhamento do paciente três vezes por semana. Esta situação se torna mais difícil nos casos de usuários oriundos de outros municípios (Santa Izabel, Vigia etc.) ou de outro estado (Maranhão).

Estas situações que dificultam o trabalho dos assistentes sociais nos CAPS e, consequentemente, na recuperação da saúde mental dos usuários expressam sem dúvida, de um lado, as contradições postas na organização institucional e, de outro, as contradições sociais do capitalismo contemporâneo que determinam as condições materiais de vida dos usuários dos CAPS, exigindo a intervenção profissional em outras expressões da questão social que extrapolam a situação de sofrimento mental, o que explica o fato de que a articulação do serviços dos CAPS com a rede de serviços de saúde, a orientação sobre os benefícios sociais etc, sejam uma das contribuições do trabalho dos assistentes sociais para a saúde mental dos usuários, pois segundo Rosa (2011), a saúde mental se configura como um campo social e político, permeado pelas contradições inerentes do capitalismo.

Sendo assim, torna-se fundamental o conhecimento acerca das expressões da questão social que não têm sido investigadas, estudadas e continuam, visto que as mesmas interferem no tratamento da saúde mental dos usuários dos CAPS, dada a complexidade do entendimento acerca da categoria "saúde mental", na medida em que esta ultrapassa o campo estritamente biológico de saúde, pois saúde mental depende das condições objetivas (moradia, trabalho, alimentação, educação, cultura, renda etc.) e subjetivas (vínculos afetivos e familiares etc.) vida em sociedade. Sob este entendimento, 
a pesquisa da realidade social dos usuários dos CAPS-Belém se torna um recurso fundamental para a formulação de propostas de trabalho e para a ultrapassagem de um discurso genérico que não dá conta das situações particulares. Essa pode ser uma trilha fértil para se pensar as relações entre indivíduo e sociedade, entre a vida material e a subjetividade, envolvendo a cultura, o imaginário e a consciência. Assim,

\footnotetext{
O principal desafio é conhecer a realidade das famílias e, para mim, se eu não tiver esses elementos na minha prática, eu fico com uma lacuna muito grande para atender individualmente alguém, porque eu considero isso como elemento chave: a família na prática do serviço social. Então o desafio é esse: (que) todo mundo que eu atenda eu conheça como é essa realidade para poder fazer os recortes pra trabalhar sem ferir a autonomia da pessoa (B2).
}

Assim, reafirma-se, de acordo com Amarante (2007), que a Saúde Mental se apresenta como um dos poucos campos de conhecimento e atuação tão vigorosamente complexos, plurais, intersetoriais, com tanta transversalidade de saberes.

\section{Considerações finais}

A elaboração deste artigo permitiu constatar que o trabalho do assistente social na Saúde Mental, especificamente nos CAPS, é baseado na perspectiva crítica, ou seja, é realizado tendo base as condições históricas e materiais de vida dos usuários que podem desencadear o sofrimento mental, que são determinadas pelas contradições sociais decorrentes das relações de classes sociais, em detrimento das práticas manicomiais. Desta forma, estrategicamente, vêm tentando resistir, fortemente, às ofensivas neoliberais de desmonte das políticas sociais públicas, nesse caso a de saúde. Além disso, identificou-se que há uma ampliação do mercado de trabalho do assistente social nessa área, decorrente da necessidade desse profissional nos serviços substitutivos às referidas práticas manicomiais, o que é legitimado na área da saúde mental, historicamente presente nas equipes de saúde desde as instituições de internação dos pacientes psiquiátricos. Como a própria história da profissão do Serviço Social, o assistente social, principalmente, a partir dos anos 1980, revê sua prática profissional, na tentativa de romper com o conservadorismo e alterar o perfil profissional. A intervenção profissional do assistente social na área da saúde mental nos dias de hoje está articulada e comprometida com o movimento dos trabalhadores e dos usuários que lutam por uma 
efetivação ao acesso de todo e qualquer cidadão aos serviços de saúde mental e da rede de serviços e direitos sociais.

Entre as principais contribuições dos assistentes sociais atuantes nos CAPS do Município de Belém-Pará, para o tratamento da saúde mental dos usuários se verificou que os profissionais fortalecem e respaldam suas ações profissionais na direção de um projeto em defesa dos interesses da classe trabalhadora, pois possibilitam a articulação com outros sujeitos sociais na construção de uma sociedade em que a maioria tivesse acesso aos direitos de cidadania. A relação dos assistentes sociais pesquisados com os usuários dos CAPS é fundamentada nas orientações contidas nos instrumentos normativos exclusivos da categoria, tais como: Código de Ética do Assistente Social, Lei de Regulamentação da Profissão no 8.662/1993, assim como, por outras legislações fundamentais para respaldar o trabalho dos assistentes sociais, na perspectiva de garantir às respostas as demandas dos usuários.

Ainda que o trabalho nos CAPS se realize em equipe, são claras as especificidades do Serviço Social, conforme foi demonstrado nos depoimentos dos profissionais/sujeitos da pesquisa que apontam como ações específicas dos assistentes sociais nos CAPS: a articulação com a rede de serviços como um ponto central no cotidiano profissional desses profissionais, pois esta ação é responsável pela resolutividade de outras demandas específicas, por exemplo: a viabilização de documentos civis, de benefícios assistenciais e previdenciários, de abrigo, de moradia e de ações dentro do território, destinados aos usuários do serviço. Assim, este artigo evidencia que mesmo compartilhando processos de trabalho e saberes com outros profissionais, se apropriando, portanto, de outros saberes, o assistente social possui uma particularidade na observação, na análise dos processos sociais e competência técnica distinta para o encaminhamento das demandas, sendo essa característica reconhecida pelos componentes da equipe de saúde.

\section{Referências}

AMARANTE, P. Saúde Mental e Atenção Psicossocial. Rio de Janeiro: Editora Fiocruz, 2007. BISNETO, J. A. Serviço social e saúde mental: uma análise institucional da prática. 2. ed. São Paulo: Cortez, 2009. 
BRASIL. Ministério da Saúde. Secretaria de Atenção à Saúde. DAPE. Coordenação Geral de Saúde Mental. Reforma psiquiátrica e política de saúde mental no Brasil. Documento apresentado à Conferência Regional de Reforma dos Serviços de Saúde Mental: 15 anos depois de Caracas. OPAS. Brasília, 2005.

BRASIL. Departamento de Ações Programáticas Estratégicas. Saúde mental no SUS: os centros de atenção psicossocial. Brasília, 2004.

CAMBAÚVA, L. G.; SILVA JUNIOR, M. C. Depressão e neoliberalismo: constituição da saúde mental na atualidade. Psicologia: Ciência e Profissão, BrasíliaDF, v. 25, n. 4, p. 526-535, 2005. Disponível em: <http://www.scielo.br/scielo.php?script=sci_arttext\&pid=S141498932005000400003>. Acesso em: 26 dez. 2016.

DUMÉNIL, G.; LÉVY, D. O Neoliberalismo sob a Hegemonia Norte-Americana. In: CHESNAIS, F. (Org.). A Finança mundializada: raízes sociais e políticas, configuração, consequências. São Paulo: Boitempo, 2005.

FALEIROS, V.P. Estratégias em Serviço Social. 9. ed. São Paulo: Cortez, 2010.

GUERRA, Y. A dimensão técnico-operativa do exercício profissional. In: SANTOS, C.M.; BACKX, S.; GUERRA, Y. (Org.). A dimensão técnico-operativa no Serviço Social: desafios contemporâneos. Juiz de Fora: Ed. UFJF, 2012.

FORTI, V. Prefácio. In: SANTOS, C.M.; BACKX, S.; GUERRA, Y. (Org.). A dimensão técnicooperativa no Serviço Social: desafios contemporâneos. Juiz de Fora: Ed. UFJF, 2012.

IAMAMOTO, M. V. O Serviço Social na contemporaneidade: trabalho e formação profissional. São Paulo: Cortez, 2004.

IAMAMOTO, M. A prática como trabalho e a inserção do Assistente Social em processos de trabalho. In: O serviço social na contemporaneidade: trabalho e formação profissional. 7. ed. São Paulo: Cortez, 2004.

. Renovação e conservadorismo no Serviço Social. São Paulo: Cortez, 2007.

. Marilda Villela. Serviço Social em tempo de capital fetiche: capital financeiro: trabalho e questão social. 7. ed. São Paulo: Cortez, 2012.

LARA, R. et al. Notas do GTP Trabalho. Questão Social e Serviço Social. Temporalis, Brasília, ano 15, n.30, p. 53-67, jul./dez. 2015.

LESSA, S. Serviço social e trabalho. Por que o serviço social não é trabalho? 2. ed. São Paulo: Instituto Lukács,, 2012.

MOTA, A. E. Crise contemporânea e as transformações na produção capitalistas. In: CEFESS. Serviço Social: direitos sociais e competências profissionais. Brasília-DF: ABEPSS, 2009. 
PRADO, Carlos. Marx e crítica à forma salário. Revista Espaço Acadêmico, Maringá, ano 11, n. 124, p. 106-116, set., 2011.

ROSA, L. C. S. Transtorno mental e o cuidado na família. 3. ed. São Paulo: Cortez, 2011.

SANTOS, C. M. dos. Na Prática a Teoria é Outra? Mitos e Dilemas na Relação entre Teoria, Prática, Instrumentos e Técnicas no Serviço Social. Rio de Janeiro: Ed. Lumen Juris, 2010.

SILVA, G. S. da. Financeirização do capital, Fundo Público e Políticas Sociais em Tempos de Crise. In: BRAVO, M. I.S.; BRAVO de MENEZES, J. S. Cadernos de Saúde: Saúde na atualidade: por um sistema único de saúde estatal, universal, gratuito e de qualidade. Rio de Janeiro: UERJ, Rede Sinus, 2011.

SIQUEIRA, M. M. N. T. Famílias: uma experiência de trabalho com grupo. Revista Ciências Humanas, Taubaté, v. 1, n. 2, 2008.

TUBINO, N. A marcha da loucura. Carta Maior, 20 jan. 2014. Disponível em: $<$ http://www.cartamaior.com.br/?/Editoria/Meio-Ambiente/A-marchada\%20loucura/3/30050>. Acesso em: 26 dez. 2016. 